\title{
THE TABLET PC INITIATIVE IN MAURITIUS - A SITUATIONAL ANALYSIS
}

\author{
Sarvesh Jugee ${ }^{1}$ and Mohammad Issack Santally ${ }^{2}$ \\ ${ }^{1}$ University of Mauritius, sarvesh.jugee1@umail.uom.ac.mu \\ ${ }^{2}$ University of Mauritius, m.santally@uom.ac.mu
}

\begin{abstract}
The Government of Mauritius has introduced tablets in the Secondary Schools in Mauritius in 2014. It is estimated that about 24000 tablets were distributed to students and educators. Secondary school students (Form IV) were given each a tablet, which was introduced as an innovative and revolutionary measure to transform educational practices in Mauritius and to align our educational system with $21^{\text {st }}$ century education concept. In this paper, we conduct a situational analysis to understand the current state of affairs with respect to the Tablet PC initiative. The study addresses issues related to the different problems that educators have faced to integrate the tablet as a mainstream educational tool and as a techno-pedagogical instrument. We found that there were a number of issues raised, which have not been sufficiently addressed prior to and throughout the implementation of the Tablet PC project. It is further observed that the satisfaction level from educators is low as compared to the expected outcome of such an ambitious project. Educators highlighted that the challenges they faced outweighed the perceived benefits of Tablet PCs while students were generally neutral about the learning experience with tablets although they admitted enjoying some benefits of the electronic device.
\end{abstract}

Keywords: 21st Century Learning, Technology-enhanced Education, Tablet PCs, Pedagogy, Teaching and Learning.

\section{INTRODUCTION}

The integration of the Tablet Personal Computer (TPC) at lower secondary level in the educational system of Mauritius by the Ministry of Education has been a controversy for teaching staff but quite a good experience for students. The aim was to innovate and provide a new sense of learning that could show some possible improvements in the local educational sector. Yet, some flaws have been discovered with the introduction of such technological devices causing a slight barrier in the traditional mode of teaching and learning. Technology is bringing a new era in the field of education today. Educators have the possibilities to change the shape of learning by manipulating latest technologies to produce positive results and influence students' achievements. However, with huge amount of money spent in technology especially in global educational sectors, there have been some disappointing results in enhancing student's performance. The introduction of latest devices, such as TPC, to facilitate learning still remains arguably a problem due to some negative leveraging of educators and also lack of training in using the tablets. The significant advancement of new educational tools exists but yet does not have a guarantee to improve students' outcomes. The main reasons for undertaking this investigation were to find out, and possibly proposed some solutions, about the major problems that influence mainly educators and students with the educational use of TPC in classrooms 
at secondary level.

\section{TABLET PCS IN EDUCATION - WHAT THE LITERATURE SAYS?}

One of the key drivers of $21^{\text {st }}$ century education is technology. The use of information and communication technologies in education is widely reported to play an important role in the development of the knowledge society. As technology becomes more accessible and ubiquitous, together with the broadband network services, education systems throughout the world, including developing countries are subject to revolutionize.

Muller et al. (2011) found that tablets are mainly used for personal purposes and that users are very passionate about particular activities such as checking mails, online social networking and interaction, research of information through search engines and also playing games. Further researches made support the fact that tablets are used mostly in weekdays and at home in places such as bedroom, kitchen, terrace and some other areas while doing common activities such as watching television, eating and other activities like cooking and to spend time while waiting.

Mobility is therefore a key feature of tablet PCs that has enabled their adoption and among a diverse type of consumers. Clarke (2013) argued that tablets would definitely replace laptops and traditional desktop computers as they demonstrate an ever-improving value in the context of productivity, functionality and cost advantages. This claim is however counter-balanced by Ozok et al. (2008) who compared task-by-task capabilities of the tablets as compared to laptop computers on the basis of reading purposes, writing and typing rationales, direct manipulating assignments and finally the form-filling activity. They found that participants did not have any difficulty to manipulate the tablets for the activities above. However, there were a high number of typing errors made on tablets for writing tasks.

The essence of mobile learning is not simply the delivery of educational contents in the form of text and multimedia on a personal device. Isaacs (2012) demonstrated that a gap still exists between familiarity and appreciation in using mobile learning to support teachers. The effectiveness and integration of a new technological device and their influence on the way of learning and teaching is a quite debatable topic of discussion. According to Motiwalla (2007), constructive pedagogical learning can be adapted to a new educational environment by identifying the strengths and limitations of a specific integrated technology. Baker et al. (2014) strongly argued that tablets have the ability to renovate learning and teaching, in numerous ways, on a global basis. They added that the distribution and delivery of applications on tablets consist of a first step only. Attaining the full prospective of mobile learning depends on a 24/7 access to digital curriculum contents that are personalized depending on the level, pace and student's strengths and weaknesses.

Xiang et al. (2006) undertook a relative analysis into investigating instructional and technological facets of using tablets as a teaching tool and found that students wanted the integration of such devices in classrooms that will promote self-learning. They argued that the effectiveness and affordability of such tablets would improve gradually on the present learning and teaching practices. Adams and Hayes (2009) testified that technology has a motivating impact on students in terms of perceived confidence of the operator of the device and enjoyment of the learners.

Dundar and Akcayir (2012) reported in their studies, about the positive awareness and the provision of enjoyment in students' minds while studying using tablet devices due to their ergonomics and easy-to-carry characteristic. They also reported about the students' preferences for electronic books, for both personal and professional development, rather than printed version. Balanskat (2013) suggested that there is no clue the tablet is more appropriate for a specific subject and hinted that most teachers would use the tablet device for browsing and searching for Internet materials or use applications to organize presentations for lectures. Furthermore, Kothaneth et al. (2012) highlighted that the accomplishment of the use of tablets in classrooms definitively relies on the endeavors to set up engaging lectures or alternative and complementary teaching styles using accessible technology.

Robson and Kennedy (2013) identified an important aspect of the use of TPC in terms of the ability to provide frequent feedbacks by collaboration and using shared screen features of tablets in viewing student's answers directly on a remote screen through the virtual network connection. As a good perspective, Goodwin (2012) advocates the benefits related with using Tablet PC in classroom settings, making emphasis towards a positive shift based on student-centered instruction and personalized learning environment, with the critical role played by teachers in promoting unique learning and engaging experiences.

The use of tablets, in educational settings, is also subject to some general issues and problems that occur and affect the day-to-day uses. One main problem faced with tablets is that they are prone to damage and 
malfunctioning if mishandled. Furthermore, Ortega (2011) supported the fact that the operating system of a TPC is a key feature that determines the applicability of tablets in educational settings.

Moran et. al (2007) found that the frequent use of tablets for educational purposes always leads to the concerns of parents and also teachers in the classroom management. Students tend to bypass educational tendencies and approached themselves to a more digital native nature to adopt some attitudes, such as texting and gaming that may intervene in their learning activities. The provision of a tablet in an educational sector must always focus on the battery life in order to support learning resources, continuous connection to available network and for interactivity sessions (Sheeshy et al., 2007). Thornburg (2012) stressed that although tablets offer free and even paid applications that can be downloaded for educational and other uses, some of them are practically not important for someone doing topics not related in the curriculum.

\section{ICTS, TABLETS AND THE EDUCATIONAL CONTEXT IN MAURITIUS}

A number of schemes have been proposed by the government over the years to transform education using ICT in the educational sector, by envisioning e-education plans and devising projects related to e-learning (Leelachand 2013). The Sankoré Project is a digital concept introduced, in April 2011, under a partnership of the French and British governments across selected African regions. It consists of the digitization of classrooms in schools and private educational institutions with the introduction and use of low-cost technological equipment such as interactive projectors and laptops. Auckbur (2013) argued that the creativeness of the learning and teaching process is expected to have a positive and long term impact on the performance of students by using a variety of pedagogical tools for both educators and learners, thus generating an enormous improvement in the educational system of Mauritius. Some measures, proposed by the Ministry of ICT (2012) that have recently been adopted by the government are:

1. The enhancement of Internet connectivity in schools and libraries to boost instant access to education, develop program competency and promote innovation.

2. Concentrating on the creation and adoption of digital contents by eradicating barriers and enhancing literacy.

3. Encouraging adoption of electronic devices and records in school premises in order to improve financial information simplicity in education.

The Ministry of Education and Human Resources (MOEHR) with the extensive support of the Ministry of Information and Communication Technology (MICT) executed a project for the distribution of TPC's to Form IV students and educators in 2013 with the concept of supporting teaching methods in class and thereafter declared that Internet connection would be made available for teacher-student and teacher-teacher interactions with the provision of better and faster connectivity in the near future. A total of about 24, 111 TPCs were dispensed to students and teachers during the period of March 2014 and June 2014 with the help of school administrations for the registration and allocation of each tablet to individual students.

\section{METHODOLOGY}

The research examined specifically the major problems affecting educators with the integration of the TPC as a mainstream educational tool in traditional classroom recently, but also discussed the brief positive aspects that have been brought at a student level of literacy. Some of the specific research questions are:

(a) What are the main problems educators are facing using the tablet devices in classrooms?

(b) To what extent the introduction of tablet devices is a positive learning experience for students at secondary level?

(c) What are the opinions of the school administrators with respect to the integration of the Tablet computers?

For the survey, qualitative and quantitative data have been used for the collection of information in both private and public secondary schools. In order to gather ample insights about the major problems affecting educators and students, a variety of research methods was considered:

(a) Online surveys (Surveymonkey.com)

(b) Face-to-face interviews

(c) Questionnaires

While online survey were used to collect large amount of data over a longer period of time, face-to-face interviews helped to gather specific conclusions on the educational use of TPC. Another useful method that 
had been exploited was the questionnaire, which had proved to be more practical, in situation where time constraint played a major problem, in order to acquire responses.

\section{RESULTS AND FINDINGS}

\subsection{Analysis of Students' Perceptions}

A sample of 76 students was surveyed online among which 43 comes from State Secondary Colleges and 33 from Private Colleges all around the island in the four different educational zones. The graph below represents the use of TPC within subjects.

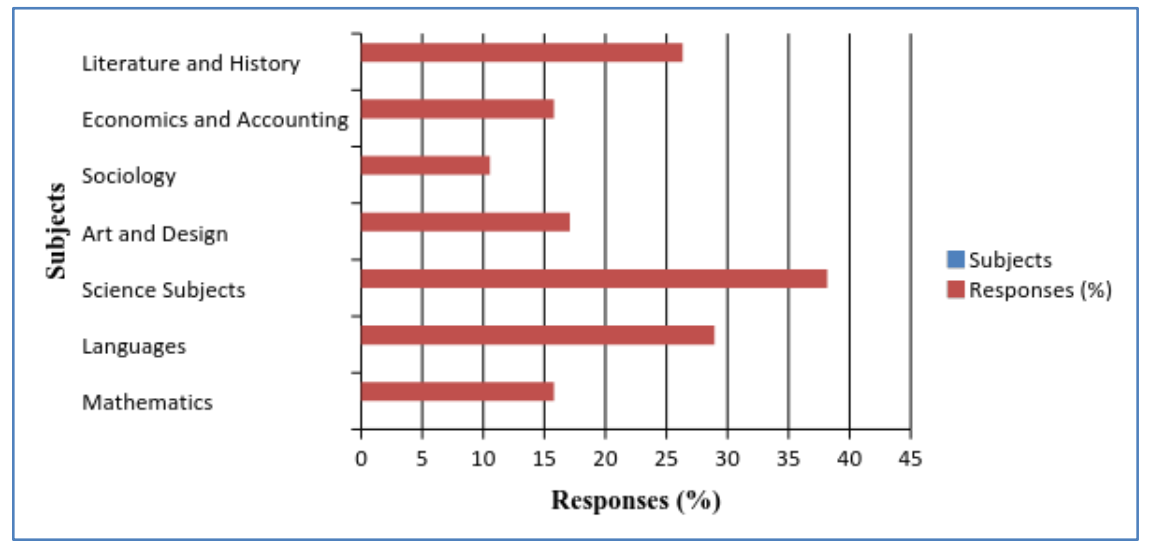

Figure 1: Subjects making use of the TPC

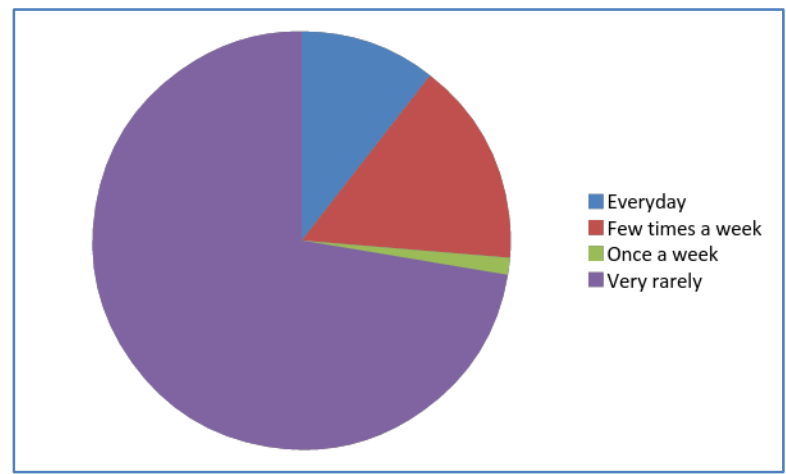

Figure 2: Use of the TPC at School (Students)

\subsubsection{TPC features already accessed with/without use of Internet connection}

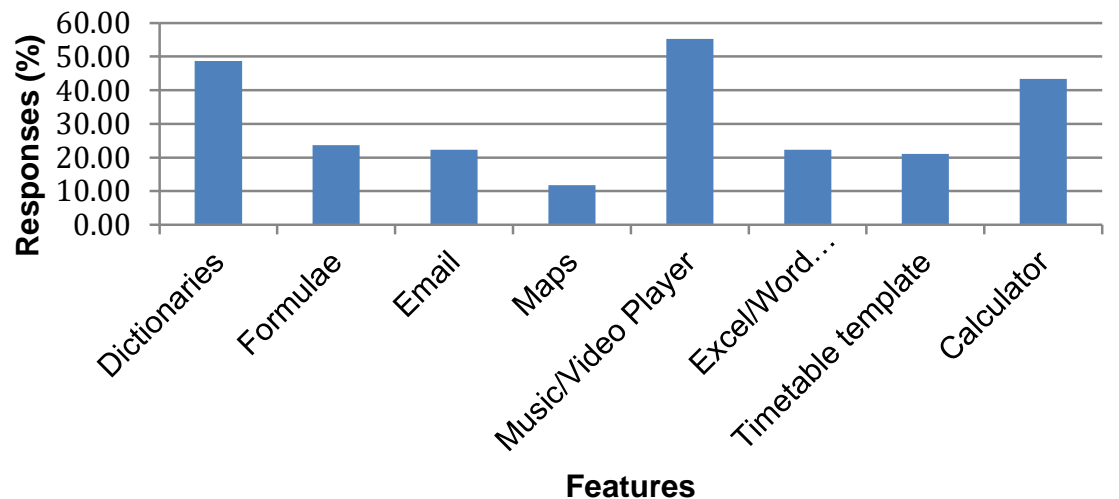

Figure 3: Features accessed with/without Internet Connection

Dictionaries (48.68\%), Music/Video Player (55.26\%) and Calculator (43.42\%) are the most common ones to be accessed more frequently. These features do not require Internet connection when used at school and they are easily accessed on the TPC through the navigation applications menu. Other features such as 
Email (22.37\%) and Maps (12.07\%) require WIFI access points in the school vicinity.

\subsubsection{Impact of TCP during lessons}

This is based on the views of students on whether TPCs have a positive impact during lessons in class. Table 1 below shows the different options available. Figure 4 shows a graphical schema of the responses obtained from the concerned people.

Table 1: Students' Views on Positive Impact of TPC in Class

\begin{tabular}{|l|l|}
\hline Option & Description \\
\hline A & You concentrate more on that you are learning \\
\hline B & You try harder on what you are learning \\
\hline C & You feel more independent in learning \\
\hline D & You understand more easily what you are learning \\
\hline E & You remember more easily what you have learned \\
\hline F & Improving group work in class \\
\hline G & Students are more engaged in tasks \\
\hline
\end{tabular}

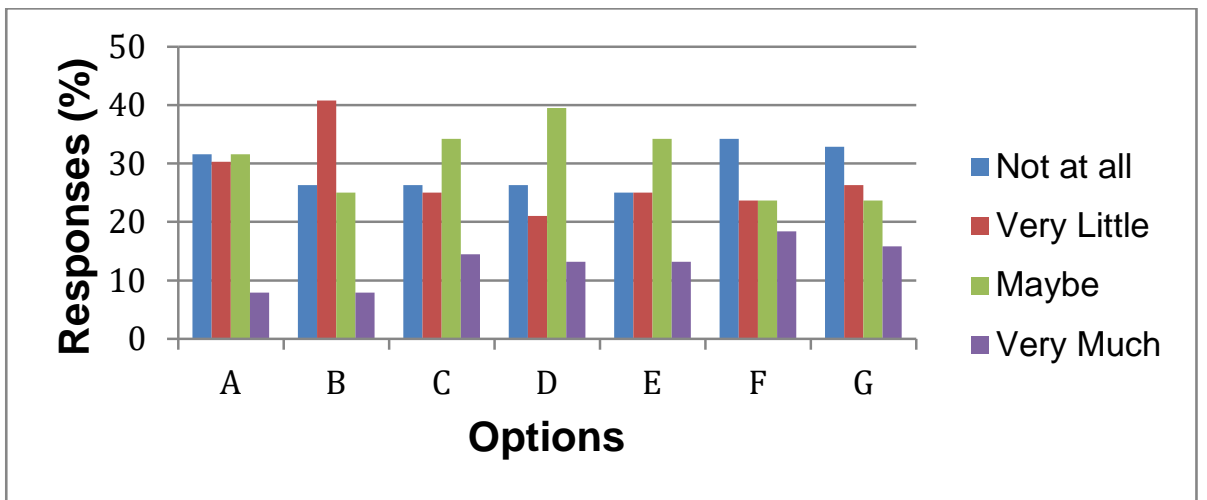

Figure 4: Responses (in \%) on whether TPC has a positive impact in class

\subsection{Analysis of Educators' Perceptions}

A sample of 253 educators was surveyed online SurveyMonkey.com, among which 53 comes from State Secondary Colleges and 200 from Private Colleges all around the island in the four different educational zones.

\subsubsection{ICT Literacies and Age Group of Educators}

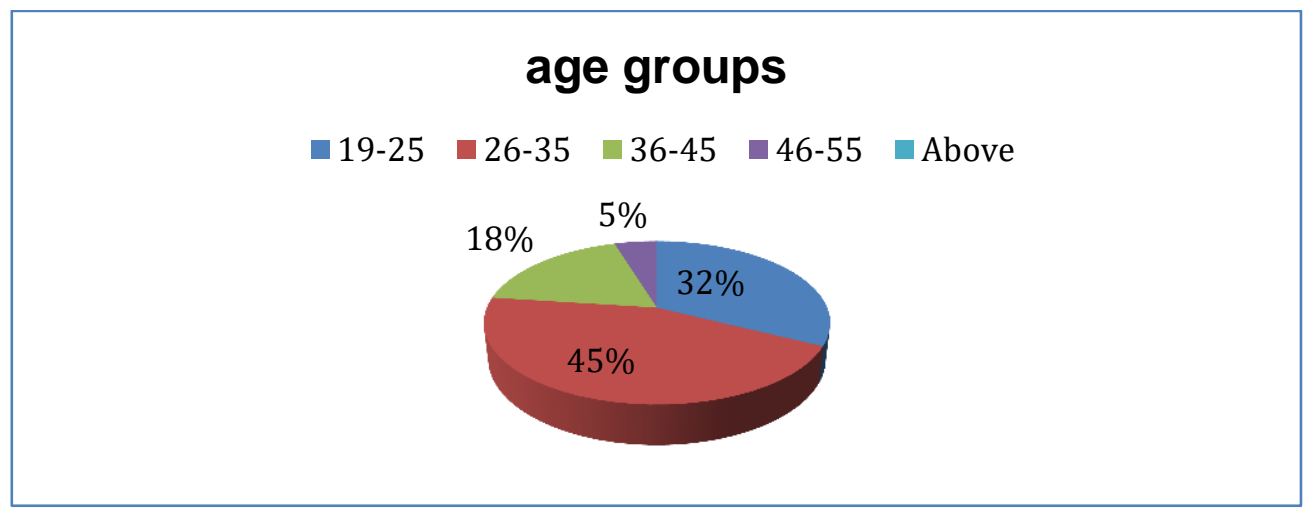

Figure 5: Age Groups Educators Surveyed 
Table 2: Number of ICT Literate (Educators)

\begin{tabular}{|l|l|}
\hline ICT Literate & Number of Respondents \\
\hline Yes & 187 \\
\hline No & 66 \\
\hline
\end{tabular}

\subsubsection{Usability and Ratings of the TPC}

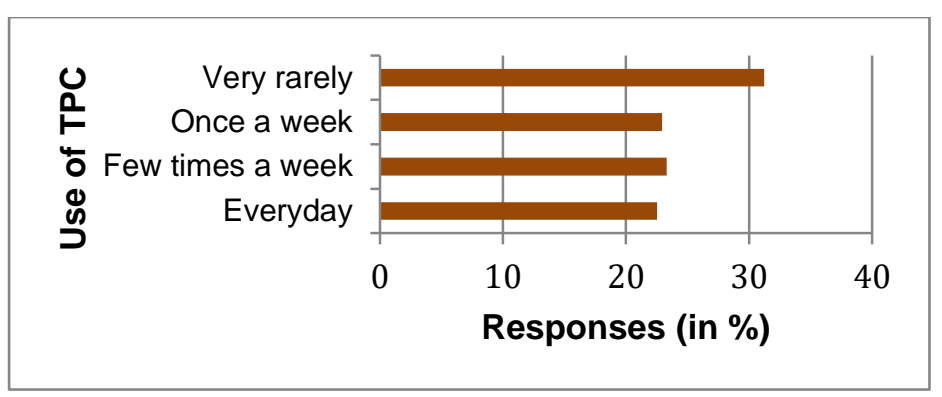

Figure 6: Use of the TPC by Educators

Figure 4 above shows the numerical responses in \% obtained through the online interview on the usability of the TPC by educators. It can be deduced that educators (31.23\%) rarely used their TPC in classroom while others made casual utilization of the tablet either in classroom or in the school vicinity. The unusualness exploitation of the TPC was dependent on the provision of WIFI access points and also the durability of their batteries in terms of use.

\subsubsection{Activities Performed in Class}

This section is based on an analysis of some activities that have been performed by educators for their respective classes using TPC. The following table shows the activities that have possibly been achieved by the teachers in their current trend of teaching with TPC.

Table 3: Educators' Activities using TCP

\begin{tabular}{|l|l|}
\hline Options & Description \\
\hline A & Browse the Internet to collect information to prepare lessons \\
\hline B & Use applications to prepare course lessons \\
\hline C & Creation of own digital materials \\
\hline D & Prepare exercises and tasks for students \\
\hline E & Download/Upload/Browse materials for class discussions \\
\hline
\end{tabular}

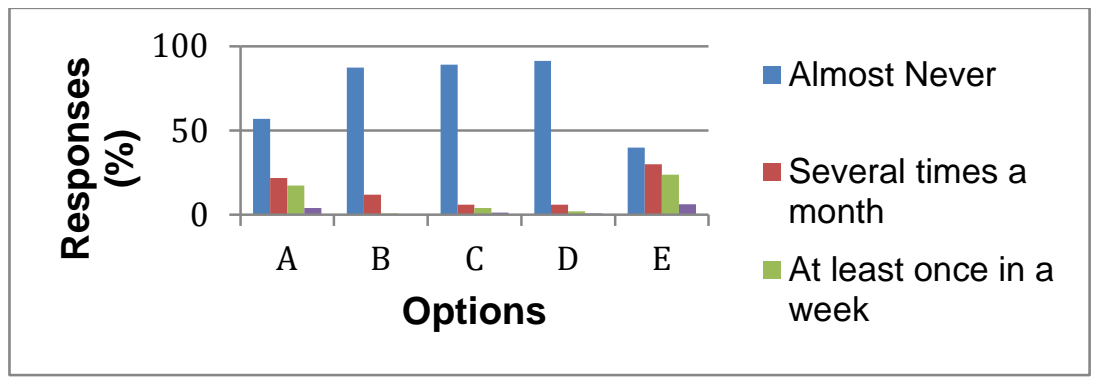

Figure 7: Trend in completing Activities using TPC

\subsubsection{Factors affecting teaching and learning with TPC in class}

This part deals mainly with some factors, according to opinions gathered, that may influenced teaching and learning in class using the TPC. Table 16 below contains information about five factors that may affect the trend in education by using TPC. 
Table 4: Factors influencing teaching and learning with TPC

\begin{tabular}{|l|l|}
\hline Factors & Description \\
\hline A & No Internet connection \\
\hline B & Lack of features \\
\hline C & Lack of Internet bandwidth or speed \\
\hline D & Lack of time to access features \\
\hline E & Lack of time to complete the syllabus \\
\hline
\end{tabular}

Figure 8 shows numerical conclusions about the opinions collected when educators were asked whether they were affected by certain aspects described in Table 16 above when they were using TPC in the classrooms.

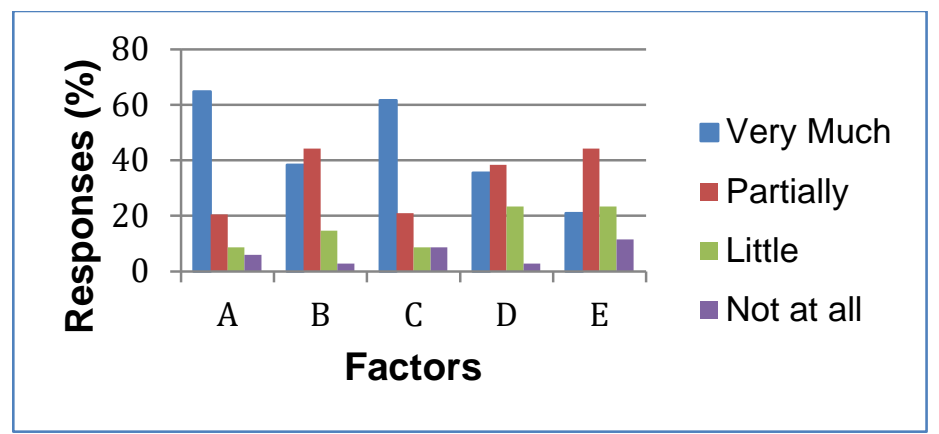

Figure 8: Responses (in \%) on whether factors tabulated influence teaching and learning with TPC

\subsubsection{Problems faced by Educators by integrating TPC in classrooms}

The introduction of such devices, supposedly to facilitate learning and teaching to take place, does have some weaknesses in terms of use. This part is basically the backbone of this research in order to have an overview of limitations related with the integration of TPC in classrooms. Educators were asked, through an open-ended question, to give all possible flaws that might not enable them to use tablets properly in teaching. A maximum of 5 possibilities were recorded per response. Figure 19 below lists all possible imperfections that certainly influenced educators.

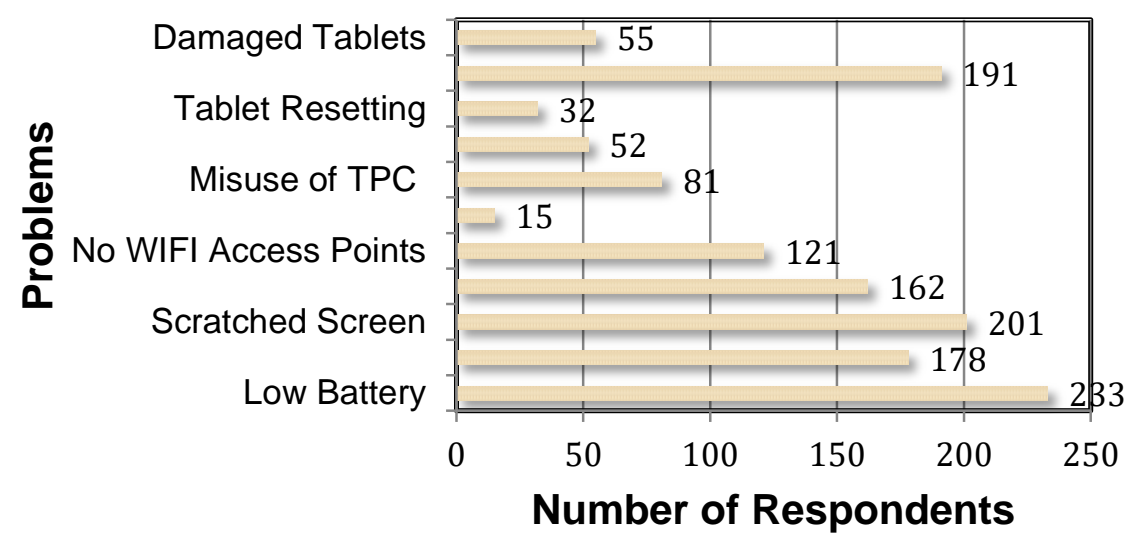

Figure 9: Problems faced by Educators using TPC in classrooms

\section{RECOMMENDATIONS, SUGGESTIONS AND FUTURE CONSIDERATIONS}

\subsection{Training of Educators}

The concept of the TPC has already been approved to facilitate the tasks of educators, but without proper training, someone cannot use a tablet. According to Kane, Rockoff and Staiger (2007), student's success is 
highly influenced by skilled and experience teachers. They also added that the number of students and any other significant variables do not affect the performance of students in class. Consequently, the use and importance of software and hardware in using the TPC have to be explained in detail to educators to facilitate their tasks in class.

\subsection{Awareness of Students and Parents}

Students and parents must be made aware of the usability steps to have a good maintenance of the TPC either at home or at school. The TPC is a fragile device in terms of misuse or portability. A mishandling of the device can bring about bad consequences for further use. It is, therefore, important for both parents and students to have a good understanding about the use of the tablets. Prior to the distribution of the mobile devices, parents should be called at school for a general meeting so that the management can explain to them the significance of using the TPC in class.

\subsection{Curriculum Review}

In order to integrate TPC in such situations, the curriculum must be reviewed in order to find a better way to provide time for the completion of topics using the technological approach. The actual program of study is so bulky that it is being accomplished in due time leaving little instances only for revision. Some subjects, like science and mathematics, need experimental applications and explanations which can be achieved with the use of tablets using applets and other animations. In order to make use of these fundamental applications, more practices and training should be implemented to facilitate this task. Thus, the syllabus needs to be reviewed in order to make use of the TPC in certain or all subjects at school.

\subsection{Assessment Modalities}

According to the actual educational system, students in lower secondary classes prepare themselves for the Cambridge examinations held in different centres in Mauritius, mainly in May/June and in October/November. Examinations are mainly pen-and-paper based type using typical methods of invigilation. The use of TPC for evaluation of progress can be considered but as mentioned, syllabus must be reviewed to accommodate examinations that can be completed either in written form, reading, or multiple-choice questions. To be able to justify progress and performance of students, continuous assessments can be done using the TPC.

\subsection{Provision of Data Access Points}

This was an important decision that was supposedly taken by the previous government but no serious offer was obtained to tender the demand. Data access points are very crucial for the use and management of the TPC in a classroom. They should be installed in the vicinity of the school to get a good coverage and an excellent WiFi connection to enable the sharing of information, the increase in mobility and collaboration among the students, and to improve responsiveness during question-and-answer time.

\section{CONCLUSION}

The introduction of the TPC, in 2014, in all secondary schools has brought a sudden change in education; educators have been influenced mostly by the use of technology instead of using traditional teaching modes. As a result, it can be deduced that the level of satisfaction from users is still yet far from what was actually expected. This sudden interruption in the current trend of education has brought some major confusion among teachers. Most of the teachers have not yet adopted the TPC mode in their delivery concept due to the fact that this can upset the termination of the syllabus in time. Some challenges, scrutinized, from the perceptions of teachers, were mainly the lack of time in using the tablets, the lack of features provided, low battery feature, level of distraction among students that influence the bulkiness of classroom management, scratched screen that promotes insensitivity to touch, no data access points to download resources and to interact with other tablets. However some benefits, observed with students, were mainly the increase in motivation, the potential portability of the device, storage of notes, and some varieties of resources used such as music players, calculators, dictionaries and some more.

The challenges overshadowed the benefits in using the TPC in classroom by educators but quite a neutral response was obtained from students. The effects of the research concluded that possible factors should be reviewed first before the re-distribution of new tablets. Some recommendations and possible suggestions have thus been proposed for a better exploitation of the TPC in the educational system. TPC has an enormous education potential as well as a negative impact if proper and adequate training is not provided. In some future researches, it would be useful to explore the use of TPC among newly admitted students in primary school and from that level, investigate their progress and overall performance to find out whether 
technology based learning will be successful in the Mauritian society.

\section{REFERENCES}

ADAMS, N., \& HAYES, C. (2009) Does Teaching with a Tablet PC Enhance the Teaching Experience and Provide Greater Flexibility? [Online]. Available from: http://www.monash.edu.au/eeducation/assets/documents/atiec [Accessed: 23th December 2014]

AUCKBUR, R. (2012) Digital Education in Mauritius: A Ministry Perspective [Online]. Available from: http://tec.intnet.mu/ [Accessed $25^{\text {th }}$ January 2015]

BAKER, A., DEDE, C. \& EVANS, J. (2014) The 8 essentials for Mobile Learning Success in Education [Online]. Available from: https://www.qualcomm.com/media/documents/files/ [Accessed $18^{\text {th }}$ January 2015]

BALANSKAT, A. (2013) Introducing Tablets in Schools: The Acer-European Schoolnet Tablet Pilot [Online]. Available from: http://files.eun.org/netbooks [Accessed: 29th December 2014]

CLARKE, P. (2013) Tablets: Will They Replace PCs?[Online].Nemertes Research. Available from http://i.crn.com/custom. [Accessed: 19th December 2014]

DUNDAR, H., \& AKCAYIR, M. (2012) Tablet vs. Paper: The Effect on Learners' Reading Performance [Online]. Available from: http://www.iejee.com/4 32012 [Accessed: 27th December 2014]

GOODWIN, K., (2012) Use of Tablet Technology in the Classroom [Online]. Available from: http://www.tale.edu.au/tale/live/teachers/shared/next practice [Accessed: 7th January 2015]

ISAACS, S., (2012) Mobile Learning For Teachers: In Africa and Middle East [Online]. Available from: http://unesdoc.unesco.org [Accessed 10th January 2015]

KOTHANETH, S., ROBINSON, A. and AMELINK, C. (2012) Tablet PC Support of Students' Learning Style [Online]. Available from: http://www.iiisci.org/journal/CV\$/sci/pdfs . [Accessed: 5th January 2015]

LEELACHAND, P., (2013) Sankoré Project - All classes to be equipped by 2017. DefiMedia. [Online] Available from: http://www.defimedia.info/ [Accessed: $10^{\text {th }}$ January 2015]

Ministry of Information and Communication Technology (2012) National Broadband Policy 2012-2020. Available from: https://www.icta.mu/ [Accessed $28^{\text {th }}$ January 2015]

MOTIWALLA, L.F., (2007) Mobile Learning: A Framework and Evaluation [Online]. Available from: http://www.qou.edu/arabic/researchProgram/distanceLearning/ [Accessed 15th January 2015]

MULLER, H., GOVE, J. \& WEBB, J. (2011) Understanding Tablet Use: A Multi-Method Exploration [Online]. Available from: http://research.google.com/pubs/archive. [Accessed: 17th December 2014]

ORTEGA, H.G., (2011) Tablets: Know Your Operating Systems [Online]. Founder Tegatech. Available from http://www.tabletpccorner.net . [Accessed: $18^{\text {th }}$ January 2015]

OZOK, A. et al. (2008) A Comparative Study Between Tablet and Laptop PCs: User Satisfaction and Preferences [Online]. International Journal of Human-Computer Interaction. Available from: http://userpages.umbc.edu . [Accessed: $17^{\text {th }}$ December 2014]

ROBSON, D., and KENNEDY, D. (2013) Using Tablet PCs For Active Learning: Learning From Other's Mistakes [Online]. Available from: http://www.merga.net.au/documents/ [Accessed: 6th January 2015]

SHEEHY, K. (2007) Tablet PCs in schools: A review of literature and selected projects [Online] Available from: http://dera.ioe.ac.uk/ [Accessed: $22^{\text {th }}$ February 2015]

THORNBURG, E.J. (2012) UsingiPads in Undergraduate Mathematics [Online] Available from http://www.usma.edu/ [Accessed: $6^{\text {th }}$ January 2015]

XIANG, W. et al. (2006) Use Of Wireless Tablet PCs As An Effective Learning and Teaching Enhancement Tool [Online]. Available from: http://www.researchgate.net/publication. [Accessed: $20^{\text {th }}$ December 2014] 